\title{
关中西部千河流域全新世古洪水事件光释光测年 研究
}

王恒松 ${ }^{(1)}$, 黄春长 ${ }^{(1 *}$, 周亚利 $^{(1)}$, 庞奖励 ${ }^{(1)}$, 査小春 ${ }^{(1)}$, 顾洪亮 ${ }^{(1)}$, 周亮 ${ }^{(1)}$

(1) 陕西师范大学旅游与环境学院, 西安 710062;

(2) 黔东南民族职业技术学院, 凯里 556000

* 联系人, E-mail: cchuang@ @sunn.edu.cn

收稿日期: 2011-10-27; 接受日期: 2012-02-10

国家自然科学基金重点项目(批准号: 41030637)、教育部博士点基金项目(批准号: 20110202130002)和中央高校基本科研业务费专项基金 项目(编号: GK200902020, GK200901007)资助

\begin{abstract}
摘要＼cjkstart通过对关中盆地西部千河流域的野外考察, 在其中游河谷段阶地前沿发现全新世黄 土-古土壤层系里夹有两层典型的古洪水滞流沉积层, 表明该地层剖面记录了古洪水事件的气 候水文信息. 通过详细观测和系统采样, 应用光释光技术中的单片再生剂量法对这些沉积物样 品进行测年, 获得了 17 个 OSL 年龄值. 结果表明千河流域特大古洪水事件发生在距今 6 5 ka. 结合沉积样品系列的磁化率和粒度成分等气候替代指标分析, 还获得了全新世洪水事件与气 候变化关系的记录. 表明在全新世早期(距今 11.5 8.5 ka), 沙尘暴活动堆积了具有过渡性质的 黄土层, 反映出气候逐渐变得暖湿. 在全新世中期(距今 8.5 3.1 ka), 对应于全球性大暖期, 各 地区出现一个强烈的成壤期, 指示气候温暖湿润, 降水量较多, 植被覆盖率增加, 生物化学成 壤作用旺盛. 但是其间在距今 6 5 ka, 由于古洪水事件堆积了两组古洪水滞流沉积层夹一个过 渡性黄土层, 导致古土壤发育中断. 全新世晚期, 即 $3.1 \mathrm{ka}$ 至今, 气候相对干旱, 形成了现代黄 土和表土层. 世界各地的环境记录表明距今 $6 \sim 5 \mathrm{ka}$ 之间是一个显著地气候恶化阶段, 被称为全 新世第二个新冰期. 千河流域在距今 $6 \sim 5 \mathrm{ka}$ 之间的气候水文事件记录, 正是该区域气候水文系 统响应全球变化的具体表现.
\end{abstract}

关键词

古洪水 光释光测年

全新世 关中盆地
古洪水又称史前洪水, 是指发生在历史时期及 其以前、未被人们观察和记录到的洪水事件. 古洪水 水文学是全球气候变化研究的前沿课题. 古洪水滞 流沉积物(slackwater deposit, 即 SWD) 是记录古洪水 事件发生信息的重要载体之一, 通过对其研究, 既可 以理解河流水文系统在万年尺度对于气候变化的响
应规律, 又可以揭示古洪水的水位、流量及其发生规 律, 为水利和防洪工程设计提供依据. 古洪水滞流 沉积物的沉积学特征是确定古洪水事件最重要的标 志 ${ }^{[1]}$. 古洪水事件断代是古洪水研究的关键问题, 通 常采用文化遗物断代法、地层对比法、放射性 ${ }^{14} \mathrm{C}$ 和 释光测年等方法得到年龄值 ${ }^{[2 \sim 4]}$. 黄土地区全新世剖

英文引用格式: Wang H S, Huang C C, Zhou Y L, et al. OSL dating of the Holocene paleoflood events on the Qianhe River in the Guanzhong Basin, China (in Chinese). Sci Sin Terrae, 2012, 42: 390-401 
面能用于 ${ }^{14} \mathrm{C}$ 测定沉积物年代的文化层和有机质材料 不易取得, 多数沉积剖面也难以找到文化遗物, 而用 于光释光测年(optical stimulated luminescence dating, 简称 OSL)的石英和长石等矿物材料普遍存在. 光释 光测年方法已被广泛地运用于考古样品、黄土和沙漠 沙等风成沉积物的断代 ${ }^{[5 \sim 8]}$. 以往释光方法对于蕴藏 着丰富环境变迁、古洪水、古地震以及构造信息的冲 积、洪积、湖积等水成沉积物面临诸多难题, 在一定 程度上阻碍了光释光测年方法在水成沉积物方面的 应用 ${ }^{[9]}$. 近十几年来, 随着光释光测年方法的发展和 技术上的改进, 使测年的精度和准确性都有了很大 的提高 ${ }^{[10,11]}$, 可以直接对河流阶地、湖泊、滨海等水 成沉积物进行测年并获得了成功 ${ }^{[4,12 ~ 16]}$, 但对于古洪 水滞流沉积物进行测年断代的研究尚不多见. 基于 此, 本文试图通过对渭河支流千河河谷阶地风成沉 积物覆盖层当中的古洪水滞流沉积物进行光释光年 龄和气候替代指标研究, 尝试建立千河流域古洪水 事件年代框架, 深入探讨古洪水事件发生的年代, 分 析古洪水事件与全球气候变化的关系.

\section{1 研究区地理背景}

千河是关中盆地西部渭河北岸的主要支流之一， 发源于六盘山脉的南端, 在宝鸡东部汇入渭河, 全长 $152.6 \mathrm{~km}$, 流域面积 $3493 \mathrm{~km}^{2}$, 多年平均径流量值 $4.85 \times 10^{8} \mathrm{~m}^{3}$, 河道平均比降为 $0.58 \%$. 该流域地势西 北高东南低, 上游分水岭海拔在 1500 2500 $\mathrm{m}$ 之间, 多为土石山区, 峡谷深遂, 地势陡峻, 植被覆盖较好; 中游流域海拔 800 1000 $\mathrm{m}$ 之间, 为黄土台原沟壑区, 原面多开辟为农田, 地表覆盖较差, 水土流失严重, 是河流泥沙主要来源; 下游流域海拔在 500 800 m, 为黄土覆盖的河谷川台区, 农业开屋强度大. 流域处 于半干旱和半湿润地区, 气候受东亚季风环流的控 制, 年平均降水量在 600 700 $\mathrm{mm}$ 之间, 年际变率较 大. 暴雨洪水主要发生在 7 9 月. 千河洪枯流量悬殊, 1954 年 8 月 16 日实测最大洪峰流量达 $3200 \mathrm{~m}^{3} \mathrm{~s}^{-1}$, 1981 年 6 月 15 日最小流量仅 $0.35 \mathrm{~m}^{3} \mathrm{~s}^{-1}$, 两者相差 达 9142 倍. 多年平均含沙量为 $10.97 \mathrm{~kg} \mathrm{~m}^{-3}$, 沙峰与 洪峰趋势一致, 最大含沙量为 $640 \mathrm{~kg} \mathrm{~m}^{-3}$ (1974 年 7 月 3 日). 千河流域人类开发历史悠久, 其中下游作为 周原的一部分, 曾经是先周和先秦时代重要的经济 文化中心, 先秦古都雍城和王陵就位于千河中游东
侧的黄土台原面.

\section{2 剖面特征及样品采集}

关于全新世古洪水滞流沉积物, 欧美学者曾经 总结出一些判别方法 ${ }^{[17 ~ 22]}$. 本项目组在对于渭河、黄 河和汉江上游全新世古洪水的研究当中, 总结出一 套更加完善的判别标准 ${ }^{[23 ~ 25]}$. 在沿着千河河谷的野 外考察当中, 我们依据这一套判别标准, 在多处全新 世沉积地层中发现了古洪水滞流沉积夹层. 本文选 择千河中游灵化村(LHC) 河段覆盖在第一级阶地上 的全新世风成黄土-古土壤剖面进行重点研究(图 1). 千河 LHC 剖面顶部高出河流平水位 10 12 m, 在坞 塌形成的新鲜剖面进行详细的观察, 发现全新世中 期古土壤层当中夹有两层水平层状构造的沉积层, 它们具有古洪水滞流沉积物的典型特征, 主要由粉 砂、粘土质粉砂和细砂构成; 在剖面垂直方向上沉积 物粒度成分、颜色、结构和构造有突变现象; 两层沉 积物之间出现风成黄土夹层, 具有显著的沉积间断. 结合我们所作的磁化率和粒度成分分析结果(图 2), 可以判定这两层沉积物为古洪水滞流沉积物 ${ }^{[23,24]}$. 这些沉积物是呈浊黄橙色粉砂和细砂, 具有水平或 者波状层理，在水平方向延伸，并且向阶地后缘方向 逐渐尖灭, 其宏观结构和构造与风成黄土古土壤形 成鲜明对比. 同时, 将千河河谷各处古洪水滞流沉积 层的分布高度进行对比分析, 判定中游 LHC 剖面古 洪水滞流沉积层是全新世洪水记录的最高位置. 根 据野外观测, 发现该组古洪水滞流沉积层包含两个 单元, 代表两期古洪水事件(SWD1 和 SWD2). 将地 层剖面清理出新鲜的垂直面, 根据其宏观沉积学、地 层学和土壤学特征, 对 LHC 剖面作了详细描述(表 1), 并自上而下进行地层划分(图 2).

在关键地层层位利用直径 $5 \mathrm{~cm}$ 不锈钢管采取了 OSL 测年样品 17 个(表 2). 同时以每 $5 \mathrm{~cm}$ 间距自上 而下采集沉积样品 110 个, 以便进行粒度成分和磁化 率测定.

\section{3 研究方法}

\section{1 等效剂量 $\left(D_{\mathrm{e}}\right)$ 测量}

在暗室安全红光下将不锈钢管里的样品两端各 削去 $2 \mathrm{~cm}$ 左右可能曝光的部分, 用铝盒盛放, 称湿 


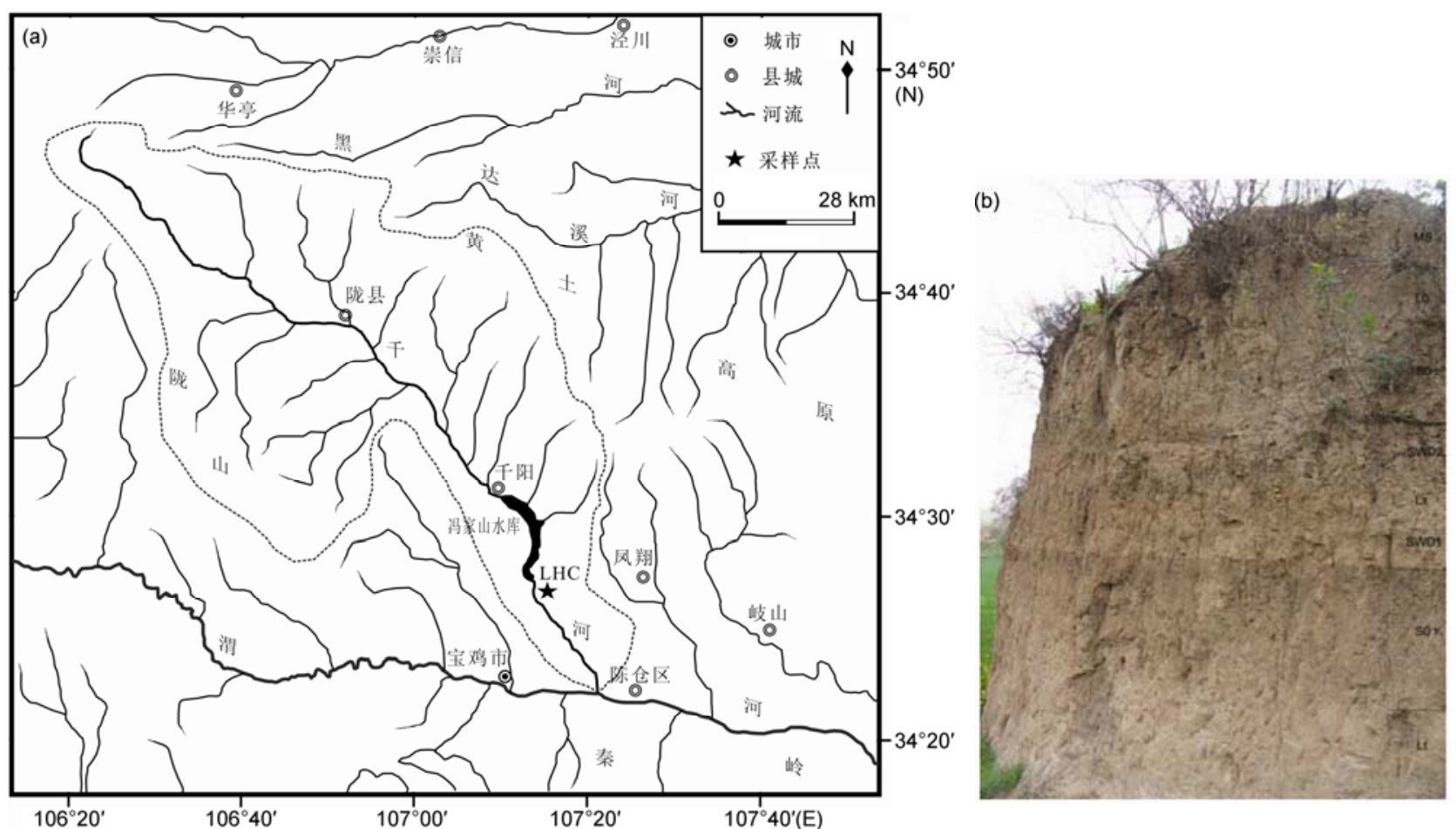

图 1 关中盆地西部千河水系和研究地点(LHC)位置图(a)和千河河谷灵化村剖面照片(b)

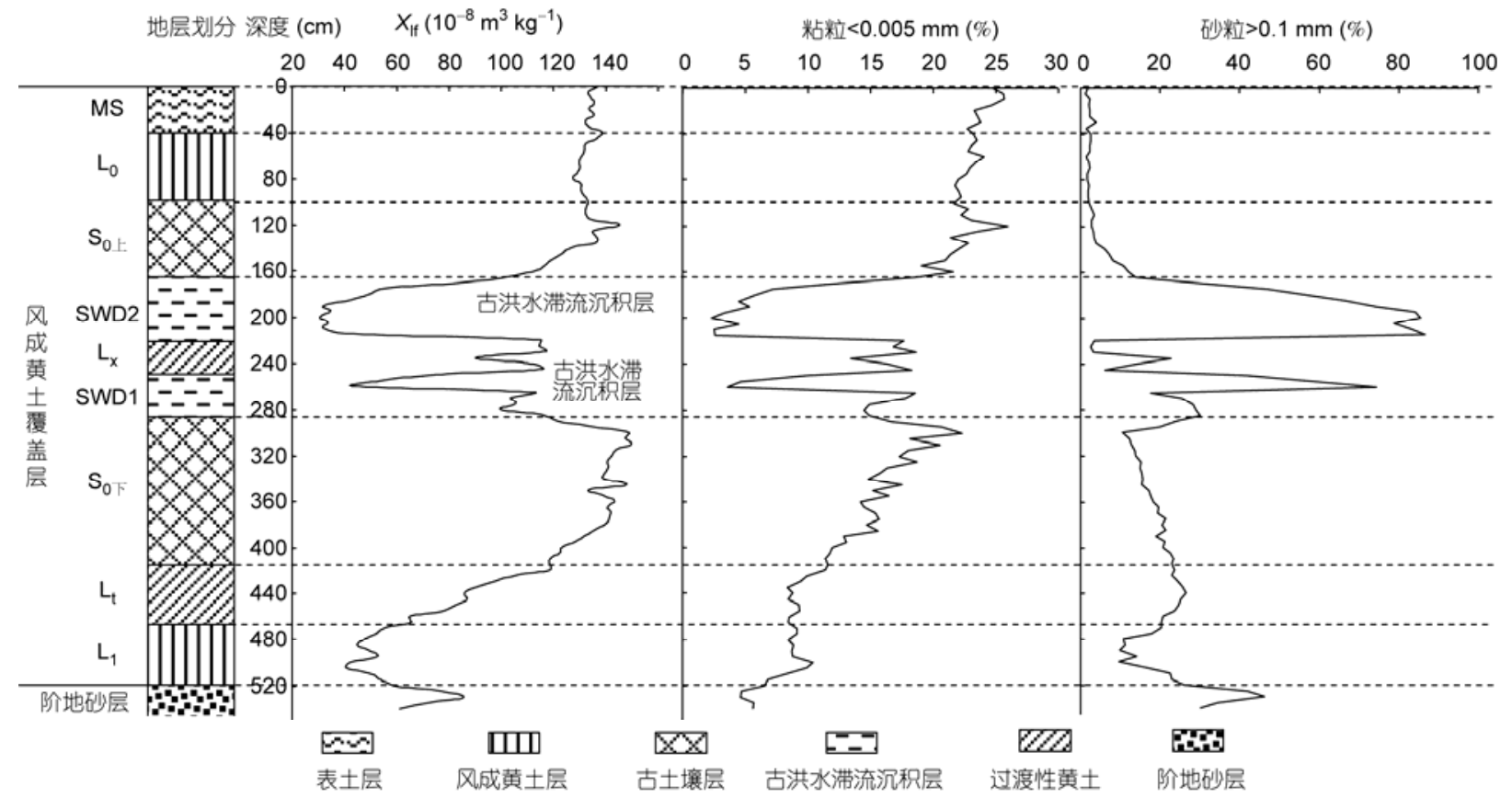

图 2 千河河谷灵化村(LHC)剖面地层划分及磁化率、粒度成分变化曲线图

重, 烘干后称干重, 并计算出含水率, 然后研磨用于 环境剂量率测定; 将中部未曝光的样品用 $30 \%$ 的
$\mathrm{H}_{2} \mathrm{O}_{2}$ 和 $10 \%$ 的 HCL 浸泡, 分别去除样品中的有机质 和碳酸盐类物质，并用蒸馏水冲洗至中性. 对于粒 
表 1 千河河谷灵化村剖面(LHC)全新世地层划分及描述

\begin{tabular}{|c|c|c|c|}
\hline 深度 $(\mathrm{cm})$ & 地层名称 & 地层符号 & 土壤与沉积学特征描述 \\
\hline $0 \sim 40$ & 表土层 & MS & $\begin{array}{l}\text { 浊橙色, 粉砂质地, 团粒结构发育, 含有大量蛏蚛孔和粪粒, 多植物根系, 典 } \\
\text { 型现代土壤 }\end{array}$ \\
\hline $40 \sim 100$ & 现代黄土层 & $\mathrm{L}_{0}$ & 浊黄橙色，粉砂质地，疏松多孔，含有少量虹蚂孔 \\
\hline $100 \sim 165$ & 古土壤层 & $\mathrm{S}_{0 \text { 上部 }}$ & 浊红棕色, 粘土质粉砂, 团粒-团块状结构, 含有大量虾蚛孔和粪粒 \\
\hline $165 \sim 220$ & 古洪水滞流沉积层 & SWD2 & 浊黄橙色, 流水沉积的细砂层, 具有水平或者波状层理 \\
\hline $220 \sim 250$ & 过渡性黄土层 & $\mathrm{L}_{\mathrm{x}}$ & 浊黄橙色, 粉砂质地, 块状结构, 含有少量蜗牛壳, 弱成壤的黄土 \\
\hline $250 \sim 295$ & 古洪水滞流沉积层 & SWD1 & 浊黄橙色, 流水沉积的细砂层和粉砂质细沙层, 具有水平或者波状层理 \\
\hline $295 \sim 420$ & 古土壤层 & $\mathrm{S}_{0 \text { 下部 }}$ & 浊红棕色，粘土质粉砂，团粒-团块状结构, 含有大量蚚蚓孔和粪粒 \\
\hline $420 \sim 470$ & 过渡性黄土层 & $\mathrm{L}_{\mathrm{t}}$ & 浊黄橙色到浊红棕色，粉砂质地，疏松多孔，含有细小钙结核 \\
\hline $470 \sim 520$ & 马兰黄土层 & $\mathrm{L}_{1}$ & 浊黄橙色, 粉沙质地, 块状结构, 疏松多孔, 含有少量蜗牛壳, 典型的马兰黄土 \\
\hline $520 \sim ?$ & 河流阶地沙层 & & 流水沉积的河漫滩相中粗沙层 \\
\hline
\end{tabular}

表 2 千河河谷灵化村剖面(LHC)光释光测年数据表

\begin{tabular}{|c|c|c|c|c|c|c|c|c|}
\hline 样品编号 & 深度(cm) & $\mathrm{U}(\mathrm{ppm})$ & $\mathrm{Th}(\mathrm{ppm})$ & $\mathrm{K}_{2} \mathrm{O}(\%)$ & 含水量 $(\%)$ & $\begin{array}{c}\text { 环境剂量率 } \\
\left(\mathrm{Gy} \mathrm{ka}^{-1}\right)\end{array}$ & 等效剂量(Gy) & OSL 年龄 $(\mathrm{ka})$ \\
\hline LHC-1 & 72.5 & $2.70 \pm 0.11$ & $11.2 \pm 0.34$ & $1.9 \pm 0.05$ & 21.90 & $3.39 \pm 0.13$ & $7.96 \pm 0.54$ & $2.35 \pm 0.18$ \\
\hline LHC-2 & 102.5 & $2.68 \pm 0.11$ & $11.7 \pm 0.35$ & $1.76 \pm 0.05$ & 21.90 & $3.31 \pm 0.13$ & $12.19 \pm 0.69$ & $3.69 \pm 0.15$ \\
\hline LHC-3 & 172.5 & $2.21 \pm 0.10$ & $10.2 \pm 0.32$ & $1.88 \pm 0.05$ & 19.30 & $3.22 \pm 0.12$ & $14.69 \pm 0.52$ & $4.82 \pm 0.24$ \\
\hline LHC-4 & 177.5 & $1.73 \pm 0.09$ & $7.48 \pm 0.25$ & $2.02 \pm 0.05$ & 16.80 & $3.02 \pm 0.10$ & $16.30 \pm 1.17$ & $5.39 \pm 0.43$ \\
\hline LHC-5 & 217.5 & $1.51 \pm 0.08$ & $7.07 \pm 0.22$ & $2.23 \pm 0.06$ & 16.30 & $3.19 \pm 0.11$ & $16.95 \pm 0.60$ & $5.31 \pm 0.27$ \\
\hline LHC-6 & 222.5 & $2.80 \pm 0.11$ & $10.9 \pm 0.33$ & $1.63 \pm 0.05$ & 17.90 & $3.26 \pm 0.13$ & $17.56 \pm 0.97$ & $5.38 \pm 0.37$ \\
\hline LHC-7 & 252.5 & $2.41 \pm 0.10$ & $10.2 \pm 0.31$ & $1.78 \pm 0.05$ & 20.10 & $3.20 \pm 0.12$ & $17.75 \pm 1.50$ & $5.54 \pm 0.52$ \\
\hline LHC-8 & 262.5 & $1.59 \pm 0.10$ & $7.46 \pm 0.32$ & $2.14 \pm 0.06$ & 16.40 & $3.08 \pm 0.11$ & $18.07 \pm 1.23$ & $5.85 \pm 0.45$ \\
\hline LHC-9 & 267.5 & $1.57 \pm 0.10$ & $9.44 \pm 0.26$ & $2.03 \pm 0.06$ & 19.52 & $2.86 \pm 0.10$ & $18.17 \pm 1.25$ & $5.94 \pm 0.49$ \\
\hline LHC-10 & 272.5 & $2.74 \pm 0.11$ & $11.4 \pm 0.34$ & $1.78 \pm 0.05$ & 18.70 & $3.37 \pm 0.14$ & $20.29 \pm 0.63$ & $6.02 \pm 0.31$ \\
\hline LHC-11 & 292.5 & $2.34 \pm 0.10$ & $10.8 \pm 0.33$ & $1.9 \pm 0.05$ & 20.16 & $3.26 \pm 0.13$ & $20.49 \pm 0.69$ & $6.28 \pm 0.32$ \\
\hline LHC-12 & 312.5 & $2.56 \pm 0.10$ & $11.1 \pm 0.33$ & $1.75 \pm 0.05$ & 20.10 & $3.23 \pm 0.13$ & $23.96 \pm 1.86$ & $7.81 \pm 0.65$ \\
\hline LHC-13 & 397.5 & $2.31 \pm 0.10$ & $9.91 \pm 0.35$ & $1.82 \pm 0.06$ & 23.00 & $3.03 \pm 0.12$ & $24.96 \pm 1.79$ & $8.31 \pm 0.69$ \\
\hline LHC-14 & 447.5 & $2.16 \pm 0.10$ & $10.2 \pm 0.35$ & $2.07 \pm 0.05$ & 24.85 & $3.29 \pm 0.12$ & $34.67 \pm 1.88$ & $10.62 \pm 0.69$ \\
\hline LHC-15 & 472.5 & $2.31 \pm 0.11$ & $10.7 \pm 0.31$ & $1.98 \pm 0.05$ & 25.00 & $3.17 \pm 0.13$ & $36.53 \pm 1.93$ & $11.65 \pm 0.78$ \\
\hline LHC-16 & 507.5 & $2.24 \pm 0.09$ & $10.3 \pm 0.30$ & $1.85 \pm 0.06$ & 25.00 & $2.99 \pm 0.12$ & $37.69 \pm 1.95$ & $12.65 \pm 0.84$ \\
\hline LHC-17 & 517.5 & $2.18 \pm 0.11$ & $9.70 \pm 0.33$ & $1.78 \pm 0.05$ & 23.18 & $2.86 \pm 0.12$ & $40.84 \pm 2.02$ & $14.02 \pm 0.90$ \\
\hline
\end{tabular}

径为 4 11 $\mu \mathrm{m}$ 的组分用静水沉降法分离, 大于 $40 \mu \mathrm{m}$ 的颗粒用湿篮分离出不同的粒级, $37^{\circ} \mathrm{C}$ 恒温烘干. 选 择 40 63 $\mu \mathrm{m}$ 的粒级组分作为本次测年材料, 取适量 用氟硅酸溶蚀 15 天, 再用 $20 \%$ 氢氟酸溶液刻蚀 40 分 钟以清除长石组分, 并用盐酸清洗样品以去除其中 的氟化物. 样品烘干后过篮, 确保所选石英的粒径范 围在 40 63 $\mu \mathrm{m}$ 之间, 然后通过 IR 检测石英颗粒的纯 度 ${ }^{[26]}$. 把提纯的石英颗粒用硅胶单层粘贴在直径为 $9.8 \mathrm{~mm}$ 的铝片中间 $5 \mathrm{~mm}$ 的区域内供仪器测量.

每个样品各制备 18 个样片, 所有样品的等效剂 量测量步骤按照单片再生剂量法 $(\mathrm{SAR})^{[10,27]}$, 在陕西 师范大学旅游与环境学院 TL/OSL 实验室, 用丹麦里 瑟(Risø)国家实验室生产的 Risø TL/OSL DA-15 型全 自动释光仪测量. 由于红外光后蓝光测年技术既能
消除石英矿物中的长石包裹体对 $D_{\mathrm{e}}$ 值的影响, 又可 提高测量精度, 同时在光释光测年中获得成功的应 用 ${ }^{[10,27,28]}$, 故本研究采用红外后蓝光(Post-IR)技术测 量 $D_{\mathrm{e}}$ 值. 测量时先用红外激发, 再用蓝光激发, 激发 光源为红外发光 $(830 \mathrm{~nm})$ 和蓝光 $((470 \pm 17) \mathrm{nm})$, 光释 光信号由 EMI9235QB15 光电倍增管测量, 探测滤光 片为 U-340, $\beta$ 辐射源为 ${ }^{90} \mathrm{Sr} /{ }^{90} \mathrm{Y}, 2009$ 年 6 月 18 日标 定源强度为 $0.10475 \mathrm{~Gy} \mathrm{~s}^{-1}$, 活度为 $1.48 \mathrm{Gq}$.

\section{2 环境剂量率测定}

样品周围的铀、针元素及其衰变子体以及钾还有 少量宇宙射线构成了样品环境剂量率的来源. 样品 的环境剂量率的贡献主要是来自周围地层中放射性 元素 $\mathrm{U}$ 和 $\mathrm{Th}$ 及其衰变子体以及 $\mathrm{K}$ 还有少量宇宙射线 
的含量. 本文的铀、针和钾含量是在中国原子能研究 院通过中子活化法得到. 宇宙射线对年剂量的贡献 是依据样品所在地点的经纬度、海拔高度、埋藏深 度和沉积物的密度, 通过辐射剂量之间的转换系数 计算 ${ }^{[29]}$ 获得. 样品含水量影响环境剂量率, 对于沉 积物样品含水量的测量值, 结合关中盆地土壤含水 量研究成果进行校正 ${ }^{[30,31]}$, 获得了样品的含水量值. 另外, 本文中的 $\alpha$ 射线的辐射效率系数值, 是参照 Lai 等 ${ }^{[32]}$ 的研究成果取值 $\eta=0.035$, 最后, 根据相关转换 参数 ${ }^{[33]}$ 获得样品的环境剂量率.

\section{3 磁化率和粒度测量}

样品的磁化率采用英国 Bartington 公司生产的 MS-2 型双频磁化率仪测量, 每个样品重复测量 3 次, 取其算术平均值. 粒度成分采用英国 Malvern 公司生 产的 Mastersizer-S 型激光粒度仪进行测定. 测量前先 用 $10 \%$ 的 $\mathrm{H}_{2} \mathrm{O}_{2}$ 和 $10 \%$ 的 $\mathrm{HCl}$ 除去样品中的有机质和 碳酸钻成分, 然后加入适量的 $\left(\mathrm{NaPO}_{3}\right)_{6}$ 充分分散后上 机重复测量 3 次, 相对误差小于 $2 \%$, 表明样品的分 析方法可行, 粒度数据可靠, 最后取其算术平均值作

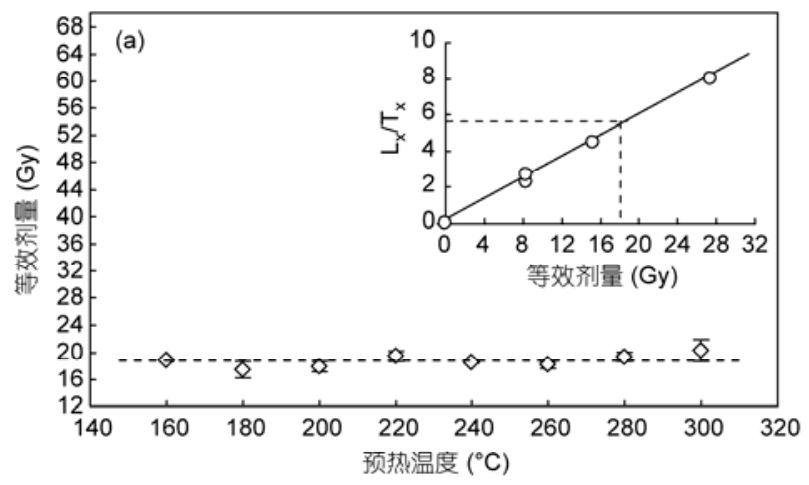

为测量结果. 对样品中粒径 $>0.1 \mathrm{~mm}$ 颗粒用耖分法测 定，并用实体显微镜进行分析鉴定.

\section{OSL 测试结果分析}

对样片进行预热是为了除去实验室辐照产生的 热不稳定信号, 迫使那些能量较低又不易晒退的陷 获电子发生转移, 从而获得较稳定的光释光信号和 准确可靠的 $D_{\mathrm{e}}$ 值. 为了获得合适的预热温度和时间, 本研究选取三个古洪水沉积样品 LHC-5, LHC-9 和 LHC-11 进行预热条件测试, 在 $200 \sim 260^{\circ} \mathrm{C}$ 之间出现 一个明显的预热坪(图 3(a)). 从图 3(a)中可知, 三个 样品在 $260^{\circ} \mathrm{C}$ 之处的预热温度比较一致, 因此, 选取 预热温度 $260^{\circ} \mathrm{C}$, 实验剂量之后的预热温度为 $160^{\circ} \mathrm{C}$, 停留 $10 \mathrm{~s}$ 做热迁移效应及剂量恢复试验(图 3(b)). 结 果表明 LHC-9 因热转移效应生成的 $D_{\mathrm{e}}$ 值是 $0.236 \mathrm{~Gy}$, 相当于样品自身年龄 $(5.94 \pm 0.49) \mathrm{ka}$ 的偏差仅为 0.077 $\mathrm{ka}$, 误差只有 $1.3 \%$, 热转移效应对等效剂量影响非 常小, 可以忽略不计. LHC-9 的剂量恢复试验表明(图 $3(b))$, 在所给的已知剂量为 $18.86 \mathrm{~Gy}$ 时, 恢复得到的

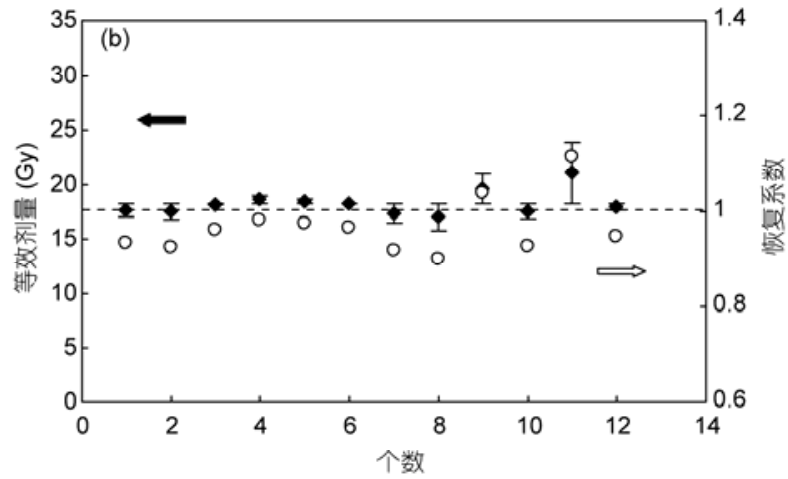

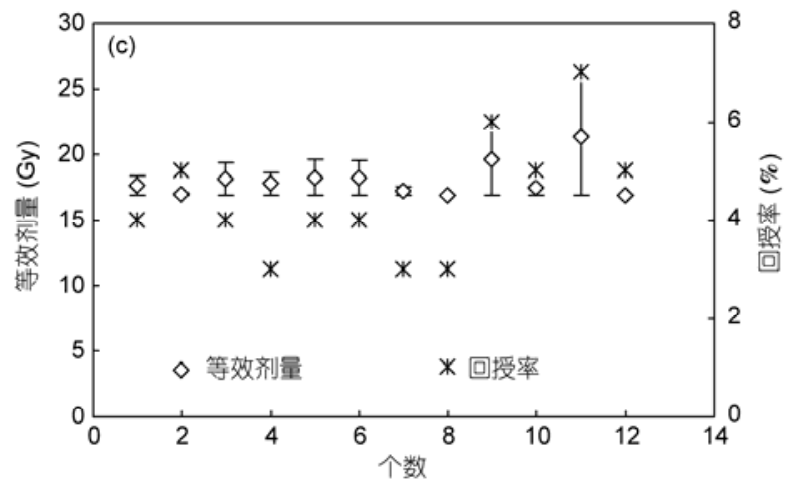

图 3 千河河谷 LHC-9 样品的预热温度对等效剂量的坪区 $(a)$ 、剂量恢复实验 $(b)$ 、回授率与等效剂量 $(c)$ 的关系 图(a)内插图为拟合的释光生长曲线 
等效剂量是 $18.22 \mathrm{~Gy}$, 与已知剂量仅相差-3.39\%, 恢 复系数在 $0.90 \sim 1.10$ 之间, 在误差范围之内 ${ }^{[10]}$. 另外, 图 3(c)给出的回授率与等效剂量的关系, 样品除了个 别测片外, 绝大多数测片回授率小于 $5 \%$. Murray 等 ${ }^{[27]}$ 认为恢复系数在 $0.9 \sim 1.1$ 之间, 回授率小于 $5 \%$, 表明 测量过程中释光感量得到了很好地校正. 在上述测 试条件下, 实验结果所得感量校正后的释光信号生 长曲线未达到饱和, 线性拟合曲线基本经过原点(图 3(a)内插图). 样品 LHC-5 和 LHC-11 除有 2 3 个测片 的回授率略大于 $5 \%$ 以及释光信号生长曲线未完全通 过原点外, 其预热温度、热转移、恢复系数及回授率
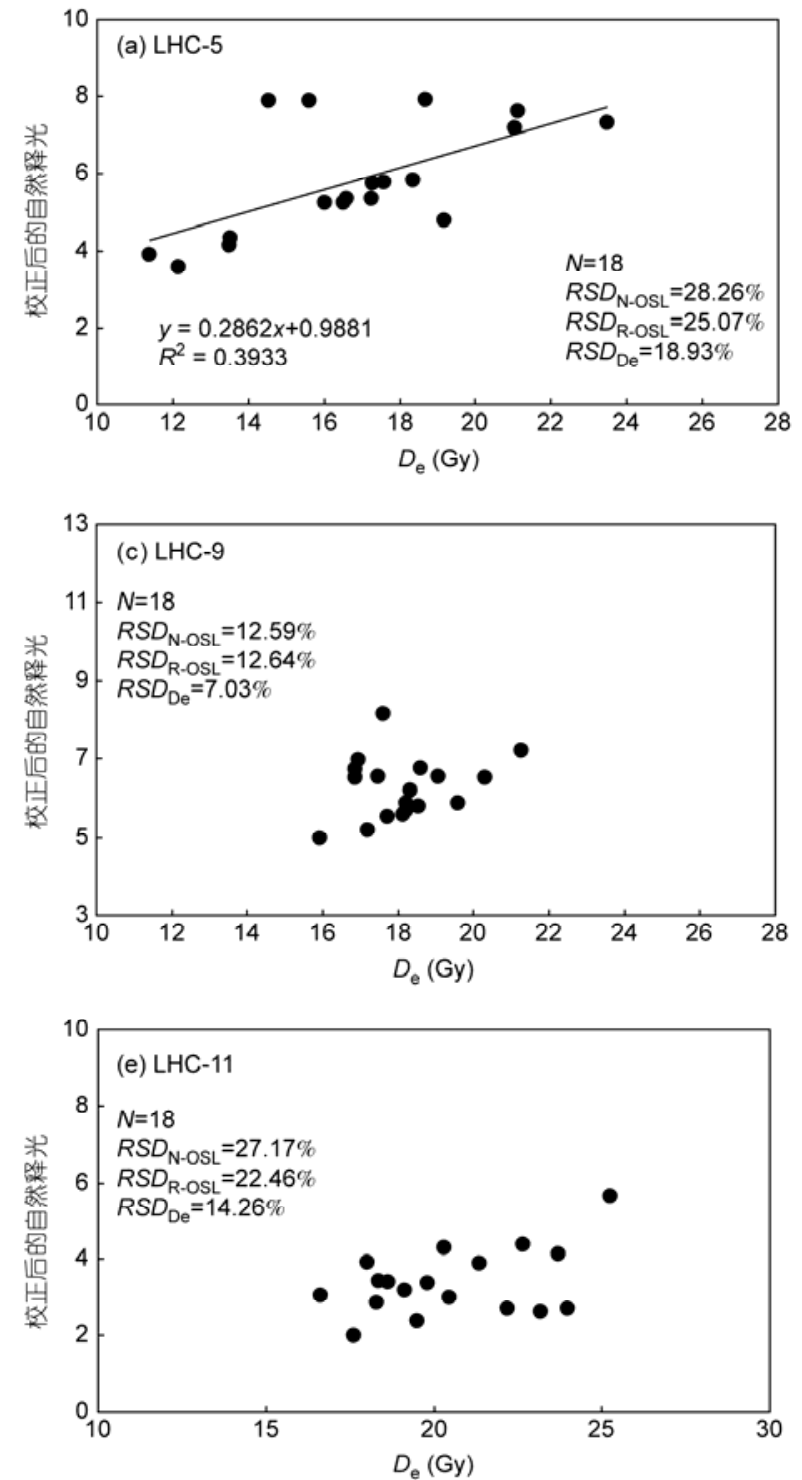

等都与样品 LHC-9 具相似特点, 由此证明我们所选 择的中颗粒 SAR 程序对剖面的所有样品都合适. 故 本研究取预热温度 $260^{\circ} \mathrm{C}$, 时间 $10 \mathrm{~s}$ 的测试条件测量 所有样品的等效剂量值.

沉积样品在埋藏前的曝光程度是测年可靠性的 关键. 一般来说，样品测试的单片等效剂量的频率分 布可以获得该样品在沉积时的曝光程度 ${ }^{[34]}$. 前人在 研究河流等水成沉积物的释光年代时，发现该类物 质的样品单片 $D_{\mathrm{e}}$ 值离散性较大, 原因是存在不完全 晒退现象 ${ }^{[35,36]}$. 图 4 中三个古洪水沉积样品的等效剂 量分布频率直方图基本反映了样品的晒退程度，样品
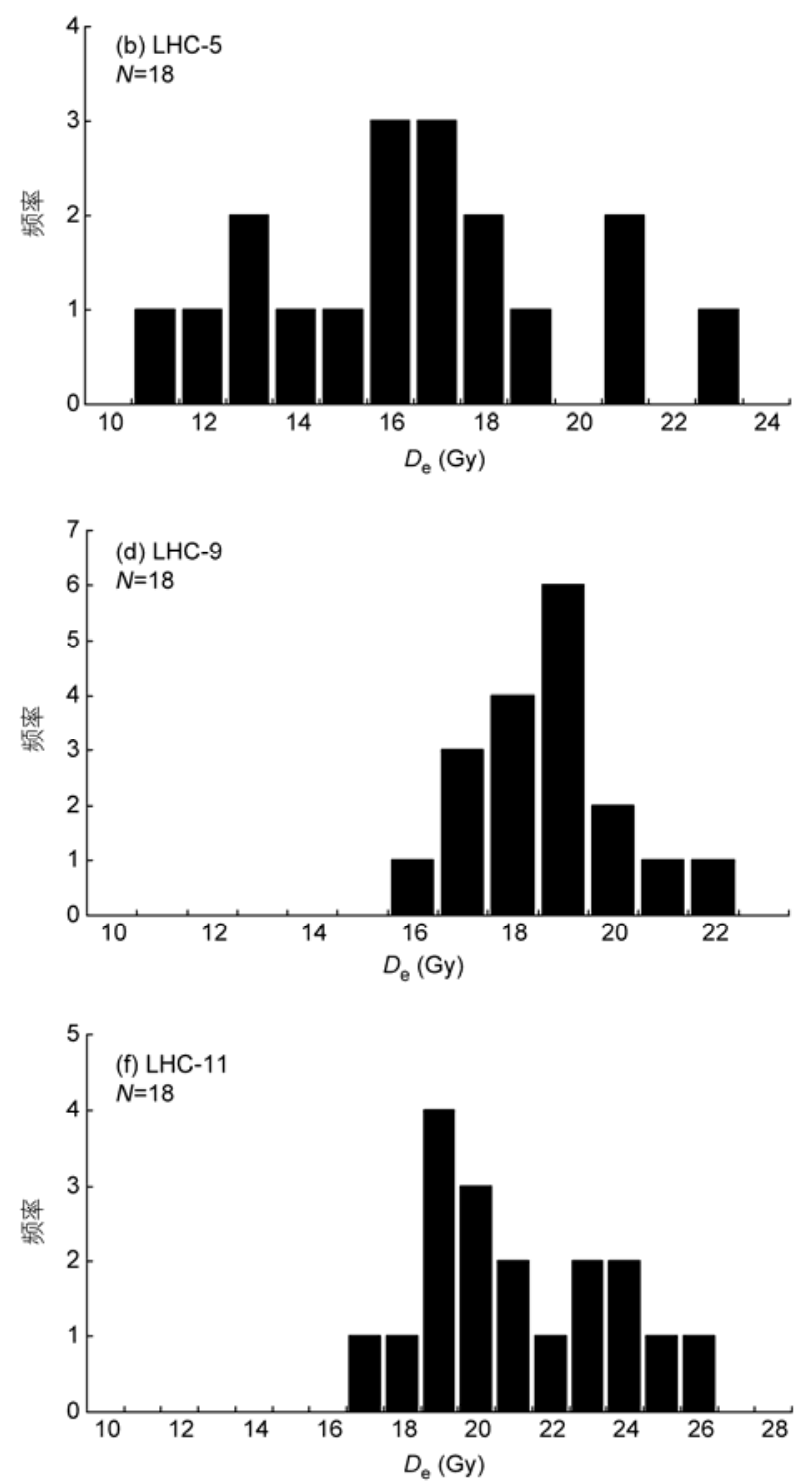

图 4 千河河谷样品的等效剂量相对于感量校正后的自然释光信号的离散图及等效剂量频率分布 
LHC-9 离散性较小, $D_{\mathrm{e}}$ 值比较集中, 而对于 LHC-5 和 LHC-11 来说, $D_{\mathrm{e}}$ 值离散度较大. 离散度用相对标准 偏差 $(R S D)$ 表示, 三个样品中各单片的等效剂量、自 然光释光信号和第一次再生剂量光释光信号的离散 度分别为 $R S D_{\mathrm{De}}, R S D_{\mathrm{N}-\mathrm{OSL}}$ 和 $R S D_{\mathrm{R}-\mathrm{OSL}}$. 如果将晒退 不彻底的样品的所有测片等效剂量值的均值作为该 样品的 $D_{\mathrm{e}}$ 值有可能导致样品的年龄偏大, 基于此我 们可以通过对比 $R S D_{\mathrm{N}-\mathrm{OSL}}$ 和 $R S D_{\mathrm{R}-\mathrm{OSL}}$ 值, 来选择晒 退较好的测片的等效剂量来计算该样品的 $D_{\mathrm{e}}$ 值, 从 而能够获得样品埋藏期间比较真实的等效剂量值 ${ }^{[37]}$. LHC-9 的 $D_{\mathrm{e}}$ 值分布直方图近似单峰正态分布, 频率 分布图相对集中, 离散性较小(图 4(c)和(d)), 变化范 围较窄, $R S D_{\mathrm{De}}$ 也较小只有 $7.03 \%, R S D_{\mathrm{N}-\mathrm{OSL}}(12.59 \%)$ 和 $R S D_{\mathrm{R}-\mathrm{OSL}}(12.64 \%)$ 非常接近, 该样品虽也为洪水沉 积物, 但其晒退比较彻底, 其感量变化得到了很好的 校正. 这也说明了古洪水滞流沉积物中释光也有完 全晒退的可能 ${ }^{[34]}$. 因此对于样品 LHC-9 的 $D_{\mathrm{e}}$ 值采用 所有样片等效剂量值的平均值.

样品 LHC-5 和 LHC-11 除了具有 LHC-9 的 $D_{\mathrm{e}}$ 值离散性外, $D_{\mathrm{e}}$ 值分布更分散, 尤其是 LHC-5 离散度 更大, 其 $D_{\mathrm{e}}$ 值频率分布图出现多峰分布, 而且 LHC-5 的等效剂量随校正后的自然释光信号强度呈明显的 线性关系, 相关率为 $39.33 \%$ (图 4(a)), $R S D_{\mathrm{R}-\mathrm{OSL}}$ $(25.07 \%)$ 较 $R S D_{\mathrm{N}-\mathrm{OSL}}(28.26 \%)$ 要小, $R S D_{\mathrm{De}}$ 也较大为 $18.93 \%$, 表明样品沉积前晒退不归零 ${ }^{[38]}$. 对于这些 晒退较差的水成沉积物样品, 等效剂量的计算根据 Zhang 等 ${ }^{[36]}$ 提供的方法. 千河河谷 LHC 剖面的样品大 多数为黄土和古土壤, 除了 LHC-3, LHC-4, LHC-5, LHC-7, LHC-8, LHC-9, LHC-10 和 LHC-11 为古洪水 沉积物样品外, 其他的黄土和古土壤样品在测量等 效剂量过程中, 同一个样品的频率分布图相对比较 集中, 离散性较小, 表明风成沉积物晒退比较彻底, 埋藏前释光信号已经完全归零, $D_{\mathrm{e}}$ 值的计算与样品 LHC-9 的方法相同, 除 LHC-9 外的其他晒退不完全 的古洪水沉积样品的 $D_{\mathrm{e}}$ 值的篮选方法与 LHC-5 的计 算相同. 这些晒退相对较彻底的样片的等效剂量的 平均值是较接近样品的埋藏剂量. 最后采用软件 AGE-exe ${ }^{[39]}$ 计算得出所有样品的光释光年龄值. 表 2 给出了 LHC 剖面所有样品等效剂量、环境剂量率及 光释光年龄值.

\section{5 讨论}

\subsection{OSL 年龄可靠性分析}

千河灵化村(LHC)黄土-古土壤剖面的 17 个样品 基本控制了各层的关键点, 界定了各地层之间的界 线. 从上到下地层逐渐变老, 释光测定获得的等效剂 量值增加, 最终求出的年龄数值也随深度增加而增大, 与地层顺序呈较好的对应关系(图 5). 总体来看, 千河 LHC 剖面测量获得的 OSL 年龄值在 $(2.35 \pm 0.18)$ $(14.02 \pm 0.90) \mathrm{ka}$ 之间, 数据误差在 $4 \% \sim 10 \%$ 的范围. 这表明千河 LHC 剖面包含了晚更新世末期和整个全 新世的风成黄土和土壤地层(图 5). 样品 LHC-15 17 分别取于剖面底部出露的马兰黄土层, OSL 年龄分别 为 $(11.65 \pm 0.78),(12.65 \pm 0.84),(14.02 \pm 0.90) \mathrm{ka}$; 样品 LHC-14 和 LHC-1 分别取于过渡性黄土层和现代黄 土层的中部, 其年龄分别为 $(10.62 \pm 0.69)$ 和 $(2.35 \pm 0.18)$ $\mathrm{ka}$, 这几组 OSL 年龄值与它们所在地层段的年龄基 本吻合. 处于剖面中间的古土壤层 $\left(\mathrm{S}_{0}\right)$ 里夹有两层古 洪水滞流沉积层, 分别是 SWD1 和 SWD2, 而 SWD1 和 SWD2 的中间又夹有一层过渡性黄土层 $\mathrm{L}_{\mathrm{x}}$. 其中 SWD1 层位于剖面深 295 250 cm 处, 被 $\mathrm{L}_{\mathrm{x}}$ 层覆盖, 取 自 SWD1 顶部 $252.5 \mathrm{~cm}$ 处的样品 LHC-7, 年龄为 $(5.54 \pm 0.52) \mathrm{ka}, \mathrm{LHC}-11$ 取于 SWD1 底部 $292.5 \mathrm{~cm}$ 深 处的样品, 年龄为 $(6.28 \pm 0.32) \mathrm{ka}$, LHC-8, LHC-9 和 LHC-10 三个样品分别取于 SWD1 层的中上、中和中 下部层位, 年龄分别是 $(5.85 \pm 0.45),(5.94 \pm 0.49)$ 和 $(6.02 \pm 0.31) \mathrm{ka}$ ，据此初步确定 SWD1 发生的时间在 全新世中期距今 6 5.5 ka 前的某个时期. SWD2 位于 剖面 220 165 cm 之间, 样品 LHC-6 取于 SWD2 底界 的下伏地层 $\mathrm{L}_{\mathrm{x}}$ 的顶部, 年龄为 $(5.38 \pm 0.37) \mathrm{ka}$, 可以界 定了 SWD2 年代的上限, LHC-5 取于 SWD2 底界, 年 龄是 $(5.31 \pm 0.27) \mathrm{ka}$, 取自 SWD2 顶界的 LHC-3 的年 龄是 $(4.82 \pm 0.24) \mathrm{ka}$, LHC-4 取于 SWD2 中部, 年龄是 $(5.39 \pm 0.43) \mathrm{ka}$, 因此, 可以把 SWD2 发生的年代确定 在距今 $5.4 \sim 5 \mathrm{ka}$ 之间. 根据测年绝对年龄数据控制和 土壤地层分析对比, 结合气候替代性指标研究, 可以 确定千河流域两期古洪水事件发生的年代在距今 6 5 $\mathrm{ka}$ 之间(图 5). 黄春长等 ${ }^{[2,40]}$ 在渭河流域的 JYC, LGT 和 NGZ 等地点黄土-古土壤剖面研究, 发现这个时段 在黄土原面和缓坡地区曾经普遍地发生过气候恶化和 土壤侵蚀与再沉积现象. 其他学者对于黄土高原南 


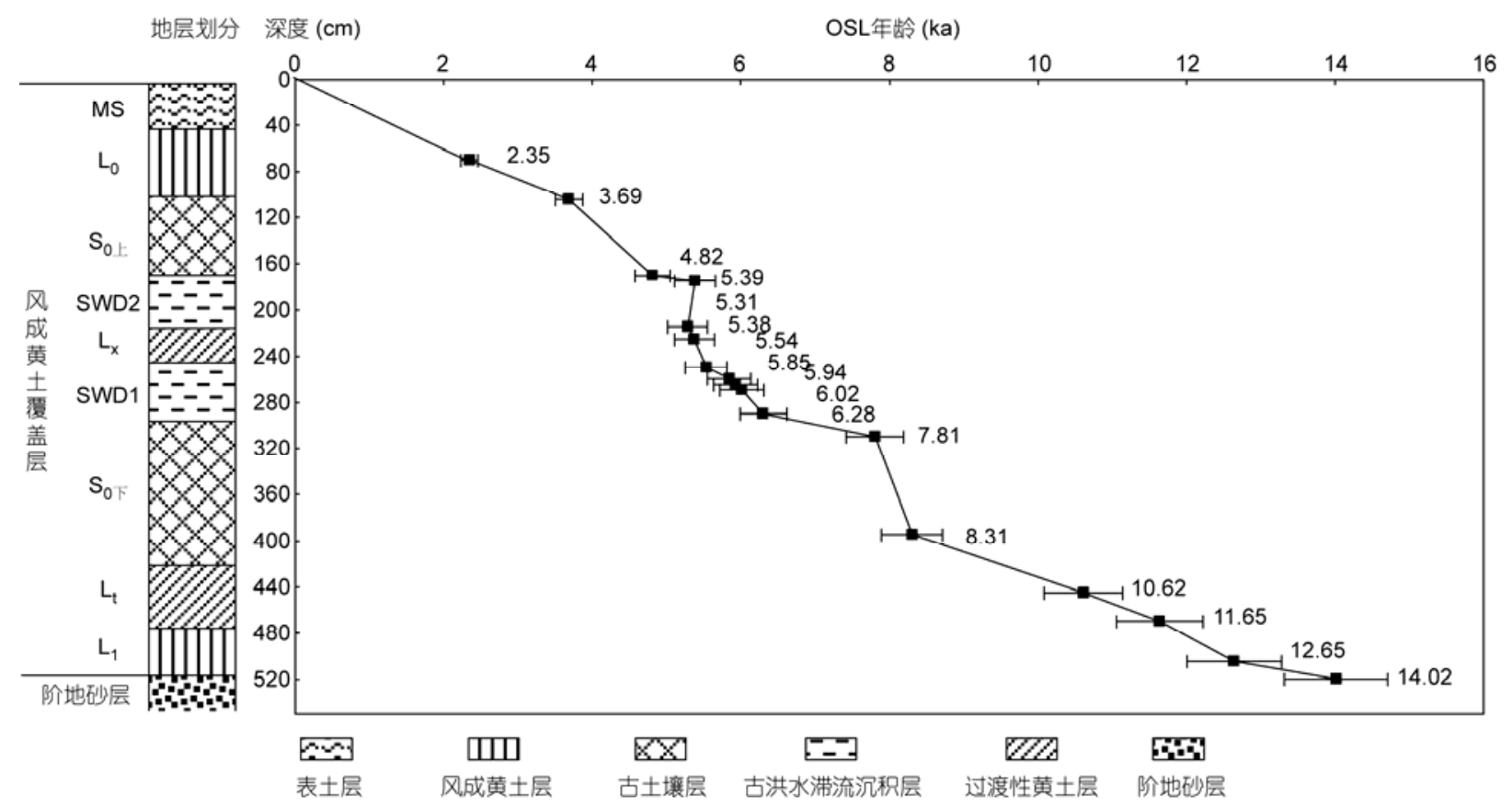

图 5 千河河谷灵化村(LHC)剖面的 OSL 年龄与地层深度关系图

部耀县剖面和蓝田剖面高分辨率的研究和 ${ }^{14} \mathrm{C}$ 测年 结果，也表明全新世中期在距今 6 5 ka 之间曾经发 生过气候的恶化现象 ${ }^{[41,42]}$. 这证明我们针对千河 LHC 剖面 OSL 年龄测定, 对于古洪水事件的界定是 正确的. 我们对千河河谷各段的考察当中, 未发现更 高的古洪水滞流沉积层记录, 故可以断定千河在距 今 $6 \sim 5 \mathrm{ka}$ 之间发生的古洪水, 是全新世以来最大的 洪水事件.

\section{2 古洪水事件与气候变化的关系}

磁化率和粒度成分作为黄土与气候变化研究的 主要替代指标，也被前人用于鉴别位于河谷的黄土剖 面中的古洪水滞流沉积层 ${ }^{[24,43]}$. 在黄土地区, 风成黄 土的磁化率值很低, 通常在 $30 \times 10^{-8} \sim 60 \times 10^{-8} \mathrm{~m}^{3} \mathrm{~kg}^{-1}$, 而古土壤在风化成壤改造过程中, 铁磁性矿物相对 富集, 故磁化率值显著增高, 在关中盆地往往在 $100 \times 10^{-8} \sim 250 \times 10^{-8} \mathrm{~m}^{3} \mathrm{~kg}^{-1}$. 千河 LHC 剖面的磁化率 变化曲线, 也基本上反映出这种规律性. 古洪水滞流 沉积物是河流洪水悬移质泥沙沉积的产物, 沉积物 中磁化率值的大小主要是由沉积物的来源和在搬运、 沉积过程中铁磁性矿物的分选沉积造成的. 在黄土地 区河流沉积物当中铁磁性矿物较少, 因而磁化率值就 比较低 ${ }^{[44,45]}$. 千河 LHC 剖面古洪水滞流沉积层 SWD1
和 SWD2 平均磁化率值分别是 $92.5 \times 10^{-8}$ 和 $49.2 \times 10^{-8}$ $\mathrm{m}^{3} \mathrm{~kg}^{-1}$, 而古土壤 $\mathrm{S}_{0}$ 下为 $136.7 \times 10^{-8} \mathrm{~m}^{3} \mathrm{~kg}^{-1}, \mathrm{~S}_{0}$ 上为 $129.9 \times 10^{-8} \mathrm{~m}^{3} \mathrm{~kg}^{-1}$. 古洪水 SWD 的磁化率明显地低 于全新世中期古土壤的磁化率值, 因而其层位在曲 线上被清楚地表现出来(图 2). 在风成黄土当中粘粒 成分含量很低, 通常在 $10 \%$ 以下, 古土壤是在气候温 暖湿润条件之下经过强烈的成壤改造, 粘粒成分富 集. 在千河 LHC 剖面, 黄土-古土壤层的粘粒成分含 量高达 10\% 25\%, 而古洪水 SWD 层当中粘粒含量低 于 $5 \%$, 故对其层位的界定也很清楚(图 2). 在黄土高 原南部地区风成黄土和古土壤当中砂级颗粒含量都 很低, 通常不超过 15\%, 而古洪水 SWD1 和 SWD2 当中砂级颗粒含量达到 $20 \%$ 80\%, 在曲线上清晰地 显示出来(图 2). 在千河 LHC 剖面中将粒度与磁化率 指标结合, 就能够有效地判明古土壤-黄土-古洪水 SWD 层的准确界限(图 2).

千河 LHC 剖面的 OSL 年龄序列结合以上三种指 标, 可知该河段第一级阶地在距今 $14 \mathrm{ka}$ 前后, 因为 构造抬升和河流下切而脱离河漫滩环境, 从而稳定 的接受风成黄土的堆积和风化成壤. 剖面 520 470 $\mathrm{cm}$ 的马兰黄土, 沉积于距今 14 11.5 ka 之间, 磁化率 值较低, 平均值为 $49.1 \times 10^{-8} \mathrm{~m}^{3} \mathrm{~kg}^{-1}$, 表明了黄土形 成时期气候冷干，在强大的西北季风环流的控制下， 
沙尘暴堆积旺盛, 降水稀少. 470 420 $\mathrm{cm}$ 是过渡性黄 土层 $\mathrm{L}_{\mathrm{t}}$, 磁化率均值为 $84.5 \times 10^{-8} \mathrm{~m}^{3} \mathrm{~kg}^{-1}$, 形成在全 新世早期(距今 11.5 8.5 ka 之间), 这时因为升温和降 水量逐渐增加, 地表植被有所恢复, 沙尘暴沉积物的 风化改造增强, 故其磁化率逐渐增加.

千河 LHC 剖面 420 100 cm 地层形成于全新世最 适宜期(距今 8.5 3.1 ka 前), 从各种分析指标可以看 出这是一个主要成壤期, 磁化率均值为 $134.4 \times 10^{-8}$ $\mathrm{m}^{3} \mathrm{~kg}^{-1}$. 这表明在东南季风控制下, 气候温暖湿润, 降水量较多, 植物生长茂盛, 生物风化强烈, 土壤淋 溶作用和粘化作用都较强. 但是在剖面 295 165 cm 深度沉积物的性质和以上三种指标, 都发生了显著 地变化. 根据野外宏观的沉积学特征和理化分析指 标, 揭示出在全新世中期大暖期的强烈成壤过程当 中, 由于在距今 6 5 ka 之间的气候恶化在千河流域 发生了特大洪水事件. 其中在距今 $6 \sim 5.5 \mathrm{ka}$ 前为第一 期洪水事件, 在距今 5.5 5.4 ka 前由于强烈的沙尘 暴活动而沉积了风成黄土, 在距今 5.4 5 ka 前发生了 第二期特大洪水事件. 这些事件导致古土壤成壤过 程出现中断, 被古洪水滞流沉积层分隔为两个亚层, 而古洪水滞流沉积层又被过渡性黄土层分裂开来. 这表明了千河流域在全新世中期并不是一个稳定不 变的温暖湿润期, 其间穿插着干旱和洪水的气候恶 化阶段. 两层古土壤层 $\mathrm{S}_{0}$ 下和 $\mathrm{S}_{0}$ 上分别形成于全新世 中期距今 8.5 6 ka 前和距今 5 3.1 ka 前. 这些都说明 在距今 6 5 ka 之间东亚季风气候格局突变, 大气系 统不稳定, 降水量异常变化, 在干旱时段降雨少, 沙 尘暴活跃, 成壤较弱, 而在洪水暴发时段, 洪流挟带 的沉积物形成厚层 SWD, 未被风化改造就被覆盖保 存下来, 使得其磁化率较低. 这与朱诚等 ${ }^{[45]}$ 的研究结 果一致. 关于这个时期的气候恶化记录, 前人有过很 多研究成果 ${ }^{[2,40]}$, 如黄春长等 ${ }^{[2]}$ 研究了渭河流域关中 盆地 JYC, LGT 和 NGZ等全新世剖面, 发现其地层结 构和磁化率、粒度等指标的变化, 系统地阐明了这个 发生在全新世大暖期当中的气候恶化事件, 施雅风 等 ${ }^{[46]}$ 也曾经认为距今 $6 \sim 5 \mathrm{ka}$ 前在我国发生了干旱、寒 冷和洪水事件, 表明自然环境条件恶化.

千河 $\mathrm{LHC}$ 剖面 100 0 cm 为距今 $3.1 \mathrm{ka}$ 以来堆积 形成的全新世晚期黄土 $\mathrm{L}_{0}$ 和表土 MS 地层. 在全新世 大暖期结束后, 受东亚季风格局变化的影响, 气候向 干旱化发展, 重新进入一个相对干旱少雨时期, 沙尘 暴堆积显著. 因为千河流域处于周原西段地区, 是先
周西周和先秦时代政治经济文化的中心地带, 各种 人类活动干扰导致土壤侵蚀和坡积物沉积参与, 故 其磁化率和粘粒含量较高. 表土层 MS 层则是距今 $1.5 \mathrm{ka}$ 以来气候转暖条件之下形成, 加之地处河谷阶 地, 受到人类农业开垦活动的扰动较大, 形成发育很 好的耕作土壤, 磁化率值较高, 粘粒含量增加.

关于距今 6 5 ka 前的气候恶化事件, 在北半球 有着多方面的证据. Bond 等 ${ }^{[4]}$ 对北大西洋深海沉积 中冰岛火山玻璃和冰筏沉积碎屑层(Ice-rafted debris, 即 IRD)研究, 获得了包括距今 $5.9 \mathrm{ka}$ 前在内的 8 次 IRD 事件. O'Brien ${ }^{[48]}$ 对格陵兰冰芯的研究, 发现冰芯 中海盐和陆源降尘浓度在全新世距今 6.1 5 ka 期间, 陆源粉尘和海盐成分浓度增大. Denton 等 ${ }^{[49]}$ 曾经调查 了世界各地冰川活动, 确定在距今 5.8 4.9 ka 时期, 多 数冰川伸展推进, 出现了全新世的第二个新冰期. 近 十几年来的孢粉、泥炭、冰芯、海洋沉积提供的高 分辨率古气候资料也显示, 中国的吉林、南海、广 东、四川、青海等地在距今 6 5 ka 期间发生过旱涝 事件的证据 ${ }^{[0 \sim 55]}$. 也有研究表明距今 $5.5 \mathrm{ka}$ 前后气候 转变, 是世界上许多地区全新世最为显著的气候变 化转折之一. 在距今 $5.5 \mathrm{ka}$ 前后的降温事件在中国地 区也有较为明显的反映 ${ }^{[56]}$. 诸如天山冰川前进、敦德 冰芯记录 ${ }^{[57]}$, 内蒙古大青山干旱寒冷且有冰缘活动 ${ }^{[58]}$, 黄土高原和关中盆地许多地点全新世大暖期古土壤 发育中断被黄土分隔 ${ }^{[59,41,42]}$, 内蒙古岱海在距今 5.5 $\mathrm{ka}$ 左右出现低湖面 ${ }^{[00]}$ 等证据, 表明该时段与世界各 地第二个新冰期的冷峰时间基本一致 ${ }^{[57]}$. 这与本文 中所测量的黄土夹层 $\mathrm{L}_{\mathrm{x}}$ 层和古洪水 $\mathrm{SWD}$ 层的年龄在 误差范围内基本一致, 表明此期间北半球气候状态 不稳定, 降水变率增大, 干旱寒冷和洪水皆有发生. 这也充分表明区域暴雨洪水的发生对于全球气候变 化十分敏感 ${ }^{[61]}$.

\section{6 结论}

关中盆地西部千河 LHC 剖面全新世黄土-古土 壤层里赋存有两层古洪水滞流沉积层. 它们是气候 变化和特大洪水事件的有力证据. 我们通过野外广 泛调查和系统采样, 结合室内实验分析研究, 应用光 释光测年技术对 LHC 剖面沉积物进行系统地断代研 究, 获得了 17 个样品的 OSL 年龄值. 基于掌握的高 密度绝对年龄控制, 以及磁化率、粒度成分等气候替 
代指标分析, 结合流域地层与气候变化对比, 建立了 千河流域全新世气候变化、沙尘暴堆积与成壤演变和 古洪水事件的年代框架, 确定千河流域在距今 6 5 ka 之间出现一个特大古洪水多发期.

通过与世界各地和我国各个区域不同类型的气 候记录的对比分析, 可知在距今 6 5 ka 期间, 在世 界各地都是一个气候恶化、冰川活动推进、冻土断 代扩张、植被退化、干旱和沙尘暴活跃的时期. 虽 然各地关于这个时期的断代有所差异, 但是气候恶 化的事实是客观存在的. 从我们在千河 LHC 剖面揭
示出的记录, 表明关中盆地西部在距今 6 5 ka 之间 气候寒冷干旱, 沙尘暴活动堆积了黄土夹层, 同时 又有两期特大古洪水事件发生. 这些造就了全新世 大暖期的古土壤 $\mathrm{S}_{0}$ 成壤中断, 分裂为两个亚层. 可 见此期间东亚季风气候格局突变, 气候波动剧烈, 大气系统不稳定, 降水变率增大, 环境条件差, 因 而干旱和洪水事件皆有发生. 这些实际上也就是全 球性气候恶化在渭河流域的具体表现形式. 它们是 渭河流域气候水文系统对于全球极端气候事件响应 的结果.

致谢杨凌、赵梅同学在野外采样和实验测试中给予的热情帮助, 若名审稿专家为完善本文提出有益建议, 在此深 表谢忱.

\section{参考文献}

1 詹道江, 谢悦波. 古洪水研究. 北京: 中国水利水电出版社, 2001. 1-89

2 黄春长, 庞奖励, 黄萍, 等. 关中盆地西部黄土台塬全新世气候事件研究. 干旱区地理, 2002, 25: 10-15

3 Huang C C, Pang J L, Huang P, et al. Holocene climatic events on the Loess Tableland in the western Guanzhong Basin, China. Arid Land Geogr, 2002, 25: 10-15

4 张家富, 周力平, 姚书春, 等. 湖泊沉积物的 ${ }^{14} \mathrm{C}$ 和光释光测年. 第四纪研究, 2007, 27: 522-528

5 周亚利, 鹿化显, Mason J A, 等. 浑善达克沙地的光释光年代序列与全新世气候变化. 中国科学 D 辑: 地球科学, 2008, 38: 452-462

6 范育新, 陈发虎, 范天来, 等. 乌兰布和北部地区沙漠景观形成的沉积学和光释光年代学证据. 中国科学 D 辑: 地球科学, 2010, 40: 903-910

7 刘德成, 王旭龙, 高星, 等. 水洞沟遗址地层划分与年代测定新进展. 科学通报, 2009, 54: 2879-2885

8 Chun X, Chen F H, Fan Y X, et al. Formation of Ulan Buh desert and its environmental changes during the Holocene. Front Earth Sci China, 2008, 2: 327-332

9 赵华, 卢演俦, 王成敏, 等. 水成沉积物释光测年研究进展与展望. 核技术, 2011, 34: 81-86

10 Wintle A G, Murray A S. A review of quartz optically stimulated luminescence characteristics and their relevance in single-aliquot regeneration dating protocols. Radiat Meas, 2006, 41: 369-391

11 Murray A S, Olley J M. Precision and accuracy in the optically stimulated luminescence dating of sedimentary quartz: A status review. Geochronometria, 2002, 21: 1-16

12 紮启顺, 赖忠平, 刘向军, 等. 晚第四纪柴达木盆地东部古湖泊高湖面光释光年代学. 地质学报, 2010, 84: 1652-1660

13 Zheng Y E, Zhou L P, Zhang J F. Optical dating of the upper $22 \mathrm{~m}$ of cored sediments from Daihai Lake, northern China. Quat Geochr, 2010, 5: 228-232

14 Zhao H, Lu Y C, Wang C M, et al. Re-OSL dating of aeolian and fluvial sediments from Nihewan Basin, northern China and its environmental application. Quat Geochr, 2010, 5: 159-163

15 白旸, 王乃昂, 何瑞霞, 等. 巴丹吉林沙漠湖相沉积的探地雷达图像及光释光年代学证据. 中国沙漠, 2011, 31: 842-847

16 雷生学, 陈杰, 刘进峰, 等. 南京长江全新世河流阶地的年代及其意义. 地震地质, 2011, 33: 391-401

17 Kale V S, Singhvi A K, Mishra P K, et al. Sedimentary records and luminescence chronology of Late Holocene palaeofloods in the Luni River, Thar Desert, northwest India. Catena, 2000, 40: 337-358

18 Benito G, Diez H A, Villalta M F. Flood response to solar activity in the Tagus basin (Central Spain) over the last millennium. Clim Change, 2004, 66: 27-28

19 Benito G, Thorndycraft V R. Palaeoflood hydrology and its role in applied hydrological sciences. J Hydrol, 2005, 313: 3-15

20 Sridhar A. A mid-late Holocene flood record from the alluvial reach of the Mahi River, Western India. Catena, 2007, 70: 330-339

21 Thorndycraft V R, Benito G. The Holocene fluvial chronology of Spain: Evidence from a newly compiled radiocarbon database. Quat Sci Rev, 2006, 25: 223-234 
22 Sheffer N A, Rico M, Enzel Y, et al. The Palaeoflood record of the Gardon River, France: A comparison with the extreme 2002 flood event. Geomorphology, 2008, 98: 71-83

23 Huang C C, Pang J L, Zha X C, et al. Extraordinary floods of 4100-4000 a B.P. recorded at the late neolithic ruins in the Jinghe River gorges, middle reach of the Yellow River, China. Paleogeogr Paleoclimatol Paleoecol, 2010, 289: 1-9

24 黄春长, 庞奖励, 查小春, 等. 黄河流域关中盆地史前大洪水研究——周原漆水河谷地为例. 中国科学 $\mathrm{D}$ 辑: 地球科学, 2011, 41: $1658-1669$

25 Huang C C, Pang J L, Zha X C, et al. Extraordinary floods related to the climatic event at 4200 a BP on the Qishuihe River, middle reaches of the Yellow River, China. Quat Sci Rev, 2011, 30: 460-468

26 Duller G A T. Distinguishing quartz and feldspar in single grain luminescence measurements. Radiat Meas, 2003, 37: 161-165

27 Murray A S, Wintle A G. Luminescence dating of quartz using an improved single-aliquot regenerative-dose protocol. Radiat Meas, 2000, 32: $57-73$

28 范育新, 赵晖, 陈发虎. 干早区湖滨沉积物中不同粒度石英等效剂量对比. 核技术, 2009, 32: 97-101

29 Prescott J R, Hutton J T. Cosmic ray contributions to dose rates for luminescence and ESR dating: Large depths and long-term time variations. Radiat Meas, 1994, 23: 497-500

30 Lai Z P. Chronology and the upper dating limit for loess samples from Luochuan section in the Chinese Loess Plateau using quartz OSL SAR protocol. J Asian Earth Sci, 2010, 37: 176-185

31 黄明斌, 杨新民, 李玉山. 黄土区渭北早塬苹果基地对区域水环境的影响. 地理学报, 2001, 56: 7-13

32 Lai Z P, Zöller L, Fuchsb M, et al. Alpha efficiency determination for OSL of quartz extracted from Chinese loess. Radiat Meas, 2008, 43: $767-770$

33 Adamiec G, Aitken M J. Dose-rate conversion factors: Update. Ancient TL, 1998, 16: 37-50

34 Bailey R M, Arnold L J. Statistical modeling of sing grainquartz De distributions and an assessment of procedures for estimating burial dose. Quat Sci Rev, 2006, 25: 2475-2502

35 Li S H. Identification of well-bleached grains in the optical dating of quartz. Quat Sci Rev, 2001, 20: 1365-1370

36 Zhang J F, Zhou L P, Yue S Y. Dating fluvial sediments by optically stimulated luminescence: Selection of equivalent doses for age calculation. Quat Sci Rev, 2003, 22: 1123-1129

37 裴树文, 张家富, 高星, 等. 三峡井水湾遗址的光释光测年. 科学通报, 2006, 51: 1443-1449

38 Li S H. Optical dating: Insufficiently bleached sediments. Radiat Meas, 1994, 23: 563-567

39 Grün R. Age.exe, Computer program for the calculation of luminescence dates. Unpublished Computer Program. Canberra: Research School of Earth Sciences, 2003

40 Huang C C, Jia Y F, Pang J L, et al. Holocene colluviation and its implications for tracing human-induced soil erosion and re-deposition on the piedmont loess lands of the Qinling Mountains, northern China. Geoderma, 2006, 136: 838-851

41 贾佳, 夏敦胜, 魏海涛, 等. 耀县黄土记录的全新世东亚冬夏季风非同步演化. 第四纪研究, 2009, 29: 966-975

42 张婷, 祝一志, 杨亚长, 等. 陕西蓝田全新世黄土 AMS $-{ }^{14} \mathrm{C}$ 测年与环境变迁. 中国沙漠, 2011, 31: 678-682

43 谢悦波, 杨达源. 古洪水平流沉积基本特征. 河海大学学报, 1998, 26: 5-10

44 潘风英, 袁丁. 兴化市乌巾荡湖泊相沉积层中鉴别洪水沉积标志的研究. 南京师范大学学报: 自然科学版, 1996, 19: 78-84

45 朱诚, 郑朝贵, 马春梅, 等. 长江三峡库区中坝遗址地层古洪水沉积判别研究. 科学通报, 2005, 50: 2240-2250

46 施雅风, 孔昭宸, 王苏民, 等. 中国全新世大暖期的气候波动与重要事件. 中国科学 B 辑, 1992, 22: 1300-1308

47 Bond G, Showers W, Cheseby M, et al. A pervasive millennial-scale cycle in North Atlantic Holocene and glacial climates. Science, 1997, 278: $1257-1266$

48 O'Brien E M. Climatic gradients in woody plant species richness-towards an explanation based on an analysis of southern Africa's woody flora. Biogeography, 1993, 20: 181-198

49 Denton G H, Karlen W. Holocene climatic variations-Their pattern and possible causes. Quat Res, 1973, 3: 155-205

50 王绍武, 闻新宇, 黄建斌. 五帝时代(距今 6 4 千年)中国的气候. 中国历史地理论从, 2011, 26: 5-13

51 孔昭宸, 杜乃秋, 许青海, 等. 中国北方全新世大暖期植物群的古气候波动. 见: 施雅风, 孔昭哀, 编. 中国全新世大暖期气候与环 境. 北京: 海洋出版社, 1992. 48-65

52 Wang L, Sarnthein M, Erlenkenser H, et al. Holocene variations in Asian monsoon moisture: A bideeadal sediment record from the South China Sea. Geophy Res Lett, 1999, 26: 2889-2892

53 Hong Y T, Hong B, Lin Q H, et al. Inverse phase oscillations between the East Asian and Indian Ocean summer monsoons during the last 12000 years and paleo-EI Nino. Earth Planet Sci Lett, 2005, 231: 337-346 
54 刘嘉麒, 吕厚远, Negendank J, 等. 湖光岩玛洱湖全新世气候波动的周期性. 科学通报, 2000, 45: 1190-1195

55 周卫健, 卢雪峰, 武振坤, 等. 若尔盖高原全新世气候变化的泥炭记录与加速器放射性碳测年. 科学通报, 2001, 46: 1040-1044

56 施雅风, 孔昭宸, 王苏民, 等. 中国全新世大暖期气候与环境的基本特征. 见: 施雅风, 编著. 中国全新世大暖期气候与环境. 北京: 海洋出版社, 1992. 1-18

57 姚檀栋, Tompson L, 施雅风, 等. 古里雅冰芯中末次间冰期以来气候变化记录研究. 中国科学 B 辑, 1997, 27: 447-452

58 Cui H T, Song C. Quaternary periglacial environment in China. In: Liu T S, ed. Quaternary Geology and Environment in China. Beijing: Science Press, 1991. 79-85

59 Huang C C, Zhou J, Pang J L, et al. A regional aridity phase and its possible cultural impact during the Holocene Megathermal in the Guanzhong Basin, China. Holocene, 2000, 10: 135-142

60 王苏民. 岱海一湖泊环境与气候变化. 北京: 中国科学技术大学出版社, 1990. 117-182

61 Knox J C. Sensitivity of modern and Holocene floods to climatic change. Quat Sci Rev, 2000, 19: 439-457 